\title{
Education and debate: Developing the place of medical humanities in medical education from school to the consulting room
}

Richard Meakin Royal Free and University College Medical School, London

In this issue's Education and debate section Evans and Greaves describe two educational developments in medical humanities. These initiatives appear to raise two important issues in the context of developing the humanities in medical education.

Evans and Greaves describe their master's programme as being "philosophy looking at humanities disciplines looking at medicine". This acknowledgement of the scope of their programme relates to their acceptance of the limits of their expertise and a respect for the complexities of the other humanities disciplines. There appears to be an important pointer here for those of us involved in developing and delivering medical humanities teaching. For those of us who come from a medical background, there is the temptation that in our enthusiasm for what the humanities can contribute to the understanding of illness and health, we go beyond our expertise. Equally, similar criticisms can be made for those from a humanities background. The first issue then is this: if medical humanities is to be accepted both in the arts/ humanities and the medical communities, and if the label of dilettantism is to be avoided, then this clarity of scope and acknowledgement of expertise must be made. The importance of this is highlighted when the second issue is considered.

Tomorrow's Doctors ${ }^{1}$ has encouraged the introduction of arts and humanities based special studies modules in medical courses. It also acknowledges the place of intercalated bachelor's degrees. In some institutions these already include some humanities-based degrees, for instance in the history of medicine. The General Medical Council (GMC) has, however, specifically left the selection criteria for entrance to medical school in the hands of the medical schools. The GMC would like "to encourage the trend towards liberalism of entry requirements," but there is evidence that both the studying of non-science A level subjects and graduate entry decrease a student's chance of being successful in gaining entry to medical school. ${ }^{2}$ If the humanities are to play an increasing role in the education of potential doctors beyond the age of sixteen then we need to consider how the entrance requirements can be influenced to allow this. Equally important, but dependent on the above, is the perception of the humanities' value within schools which advise students on their career paths. Otherwise students will choose not to take arts and humanities A levels or bachelor's degrees such as that described by Greaves and Evans.

If a broad, science-and-humanities-based, interdisciplinary education for future doctors from school to the consulting room is to be achieved then both of these issues need to be considered in our work.

Richard Meakin is Senior Lecturer and Co-director of the Medical Humanities Unit, Department of Primary Care and Population Sciences, Royal Free E University College Medical School, London.

\section{References}

1 General Medical Council. Tomorrow's doctors. London: General Medical Council, 1991.

2 McManus IC. Factors affecting likelihood of applicants being offered a place in medical schools in the United Kingdom in 1996 and 1997: retrospective study. British Medical fournal 1998;317:1111-17. 